\title{
Characterization of littered face masks in the southeastern part of Turkey
}

\author{
Ceyhun Akarsu $^{1}$ (D) Özgecan Madenli ${ }^{2}$ Ece Ümmü Deveci ${ }^{2}$
}

Received: 9 February 2021 / Accepted: 20 April 2021 / Published online: 24 April 2021

(C) The Author(s), under exclusive licence to Springer-Verlag GmbH Germany, part of Springer Nature 2021

\begin{abstract}
A possible source of microplastics has started to be released into nature because of the single-use face masks that protect us against the spread of COVID-19 and are being thrown onto the streets and into seas and nature. This study aims to estimate the amount of face mask use during the COVID-19 pandemic in Turkey, thereby expressing our concerns about waste management and plastic pollution and calling on appropriate solid waste management policies and governments to take the necessary measures to formulate their strategies at all levels. In this context, the number of masks in an area of $1 \mathrm{~km}^{2}$ in 3 different cities was determined theoretically and experimentally. Fourier transform infrared spectroscopy (FT-IR) and scanning electron microscope (SEM) were also used to evaluate plastic polymer characteristics of the single-use face mask. It was determined that the three cities produce roughly 10 tons of face masks in a day. With the increasing use of single-use plastics, the impact of face masks on microplastic pollution is of great concern. Although studies on the recovery of disposable masks continue, the level is insufficient. Therefore, studies to be carried out on technologies that will enable the repeated use of masks are important.
\end{abstract}

Keywords COVID-19 $\cdot$ Face masks $\cdot$ Microplastic pollution $\cdot$ Soil pollution $\cdot$ Water pollution

\section{Introduction}

The coronavirus, which first emerged in Wuhan, China, in December 2019 soon became a global pandemic. Life came to a standstill after the World Health Organization (WHO) declared that the disease could spread through the air (Velavan and Meyer 2020). Many governments at all levels have adopted to use face masks as a first measure to gradually ease restrictions. These masks, which are frequently used by individuals who are carrying on with their work/social life, are a means of protection from the virus (Chintalapudi et al. 2020). In March 2020, the early days of the pandemic, WHO announced that approximately 90 million masks were needed every month worldwide (WHO 2020). However,

Responsible Editor: Philippe Garrigues

Ceyhun Akarsu

ceyhunakarsu@mersin.edu.tr

1 Department of Environmental Engineering, Mersin University, Mersin, Turkey

2 Department of Environmental Engineering, Nigde Ömer Halisdemir University, Niğde, Turkey according to May 2020 data, $88 \%$ of the world's population live in countries that require the use of masks in public places. Therefore, it can be said that an average of 6.7 billion people needs to wear a mask to carry on with their daily/social life (Mask4all 2020).

Nonwoven fabrics are generally defined as webs of fibers or filaments bonded together mechanically, thermally, or chemically (Karthik et al. 2016). Most disposable masks are made of melt-blown nonwoven fabrics (mostly polypropylene). Nonwoven polymers are a cost-effective material for the production of masks and similar products and have a lower production cost. The microorganism filtering efficiency is high due to its micropattern structure. Therefore, they are used quite frequently in face mask production (Zhao et al. 2020).

Once the organic polymer products such as face masks are thrown away, it breaks down as macroplastic or microplastic caused by exposure to environmental factors such as the sun's radiation or rain (Gregory and Andrady 2003). The plastic products we use daily take tens to hundreds of years to decompose in nature (Moore 2008). If not properly managed, plastic waste can travel great distances and accumulate in large quantities in terrestrial environments, shorelines, and open oceans (Zbyszewski and Corcoran 2011). These plastics undergo physical and biochemical degradation (mechanical 
erosion, light-induced degradation, and biological degradation) and turn into microplastics that are more difficult to control (Ó Briain et al. 2020).

Plastics with a particle size of less than $5 \mathrm{~mm}$ are called microplastics (Zhang et al. 2017). There are two main sources of microplastics: (1) synthetically produced microsized plastics and (2) the breaking down of macroplastics into microplastics by environmental factors (Akarsu et al. 2020). Many studies have been conducted on the detection, quantification, and identification of microplastics in the soil/aquatic ecosystem (Corradini et al. 2020; Gerolin et al. 2020). Microplastics have a high volume-to-surface ratio and a long degradation time (Barnes David et al. 2009). Particle size is considered the most critical factor when evaluating the effect of microplastics on the marine ecosystem. It has been proven in the studies that the toxicity effect changes depending on the particle size (Jeong et al. 2016). In another study investigating the effect of microplastic size on organisms, it was reported that the growth of copepod Tigriopus japonicus was significantly delayed and survival rate decreased when exposed to microplastics with a size of $0.5 \mu \mathrm{m}$ or less, while 6 - $\mu \mathrm{m}$-sized microplastics were reported to have no significant effect (Lee et al. 2013).

Most of the studies on plastic-microplastic pollution have focused on the marine ecosystem. Studies on terrestrial plastic pollution and its possible effects are very few. However, the soil is the first environment to which plastics are transported. Approximately $32 \%$ of the existing plastic wastes are currently mixed with the soil (Kumar et al. 2020). It has been reported that the presence of microplastics significantly affects microorganisms, soil density, water holding capacity, and evaporation rates (Huerta Lwanga et al. 2016; Scheurer and Bigalke 2018; Lu et al. 2019). In addition to all these effects on the soil biota, it is predicted that small-sized microplastics $(<1 \mathrm{~mm})$ can mix into groundwater through irrigation. WHO and various other authorities predict that the coronavirus pandemic will continue for at least several years. Accordingly, the use of face masks will also continue for some time, meaning that the possible threats of microplastics to the soil will increase.

Face masks are collected in the status of special hazardous waste in Turkey as in many countries. However, they easily are transported to the aquatic ecosystem by rivers, wind, drainage systems, shipping routes, or human activities (Corcoran et al. 2009; Barnes David et al. 2009). In this way, the masks in the environment may create a risk of macroplastic pollution and then microplastic pollution soon. Research on microplastic pollution in the seas continues on a global scale; however, face masks will make it difficult to find solutions to the existing problems.

People started to socialize again with the reduction of the first wave effect of the pandemic and disposable masks strewn around the streets, parks, beaches, and oceans of many cities as reported by Brando (2020). With the increase of similar studies, the regional distribution numbers and waste management methods of single-use masks became a subject of interest (Akber Abbasi et al. 2020). Researchers have started to report the number of used masks in their country and the number of regularly disposed ones (Aragaw 2020).

According to UN estimates, up to $75 \%$ of all coronavirusrelated plastic could end up as waste in oceans and landfills (UNCTAD 2020). It has been estimated that as a result of the pandemic, 129 billion face masks and 65 billion gloves are used globally per month (Prata et al. 2020). Assuming each face mask weighs $4 \mathrm{~g}$ and each glove weighs $5 \mathrm{~g}$ (manufactured product), that is 841,000 metric tons of medical waste generated per month. It is also known that medical waste is included in the scope of nonrecyclable waste according to the current legislation and regulations. Ultimately, most plastic waste around the globe ends up in the aquatic/soil ecosystem.

Moreover, reports have been published stating that disposable masks are not properly disposed of and that they are not sufficient in waste management (Sangkham 2020; Dharmaraj et al. 2021). This study provides insight into the contribution of the significant change with COVID-19 for plastic per unit area to plastic pollution and the environmental effects of this change.

In this study, we calculated the approximate number of face mask usage in Turkey and the three cities in the country, leading to a rough estimate on (micro) plastic content in the environment. Plastic polymer characteristics of the single-use face mask were evaluated using Fourier transform infrared spectroscopy (FT-IR) and scanning electron microscope (SEM). Another objective was to estimate the face mask use of each city during the pandemic and compare the actual case values with the theoretical values. The results will enable a better understanding of the current situation and can be used to take action in terms of new policies and strategies regarding waste management.

\section{Methods}

\section{Sampling area and method}

Mersin and Adana are located in the southeast of Turkey and are very populous cities of the northeast Mediterranean. At the same time, these cities constitute $4.2 \%$ of Turkey (Fig. 1). The distance between Adana and Mersin cities is very short ( 80 $\mathrm{km}$ ), is located in the Mediterranean Region, and having the same climate makes the cities socioculturally similar. On the other hand, Niğde, which has only one sixth of the population of Mersin and Adana, is located $200 \mathrm{~km}$ north of these cities. Whether these factors are important or not was determined by comparing the cities. 
Fig. 1 Locations of the three cities in southeastern Turkey

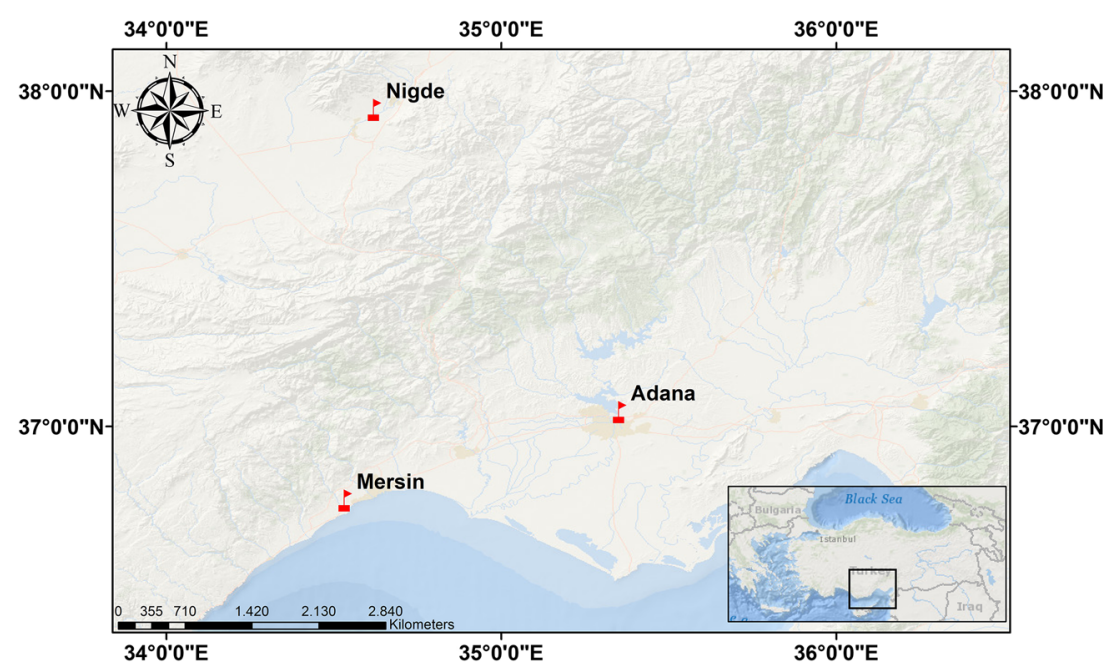

The three cities represent $5 \%$ of Turkey, both in terms of population (approximately 4 million people) and in surface area $\left(40,000 \mathrm{~km}^{2}\right)$. Thus, the obtained results were considered sufficient to make a meaningful inference of the whole country. A common aspect of these cities is that the existence of the universities in this region causes the formation of a dense population and consumption dynamics.

The Mediterranean, in which Mersin and Adana are located, is already susceptible to high levels of pollution due to its huge coastal population. Studies conducted in the eastern Mediterranean have reported that hundreds of millions of microplastics are discharged into the seas every day (Akarsu et al. 2020). Therefore, any work to be carried out on microplastics in this region is of vital importance for the sustainability of the aquatic ecosystem.

In this study, a perimeter of $1 \mathrm{~km}^{2}$ in all three cities was determined by the geographical information system (GIS), and the masks found within these perimeters were collected. Each mask was collected with metallic forceps and was placed in an individually sealed bag. Then the coordinates of the places where the mask was located were noted. Before the structural deterioration of the masks was examined, they were protected from UV light. The face masks were disinfected by spraying 70\% ethanol solutions. It is known that polypropylene and polyethylene are chemically resistant to ethyl alcohol (Calpaclab, 2021). Then FT-IR, SEM, and weighing analysis were performed. Analyses were carried out following standard methods.

\section{Calculations}

In order to make a waste management plan, it is necessary to calculate how much waste is generated. This study also estimated the number of face masks used for the protection from the virus for each city. The number of face masks used per day was estimated using an equation adapted from that of
Nzediegwu and Chang (2020) and Sangkham (2020) and is as follows:

$D_{\mathrm{fm}}=P x U_{p} x F_{\mathrm{mar}} x F_{\mathrm{MGP}}$

where $D_{\mathrm{fm}}$ is daily face mask use (pieces), $P$ is the population (persons), $U_{P}$ is the urban population (percentage), $F_{\mathrm{MAR}}$ is face masks' acceptance rate (this rate was accepted as $80 \%$ in this study), and $F_{\mathrm{MGP}}$ is the assumption that each person in the general population uses one face mask a day.

The estimated daily face mask per square kilometers of each city was calculated as follows:

Face masks per $\mathrm{km}^{2}$

$=$ estimated daily face mask use/city surface area $\left(\mathrm{km}^{2}\right)$

The theoretical and experimental weights of face masks per $\mathrm{km}^{2}$ were calculated as follows:

Weight of face masks per $\mathrm{km}^{2}\left(\mathrm{~g} / \mathrm{km}^{2}\right)$

$=$ Theoretical/experimental weight of mask

$\times$ Theoretical/experimental face masks per $\mathrm{km}^{2}$

\section{Analysis}

The deterioration of the chemical structures of the masks was determined with Fourier transform infrared (FT-IR) and scanning electron microscope (SEM) analyses. Furthermore, the uncontrolled distribution of the masks per unit area was evaluated, and the effect of the masks on the microplastic pollution for each city was determined according to Akber Abbasi et al. (2020).

Disposable face masks can be manufactured from different polymeric materials. Polypropylene (PP), polyurethane (PUT), polyacrylonitrile (PAN), polystyrene (PS), 
polyethylene (PE), and polyester (PES) are the most common types of polymer materials used (Aragaw 2020). Therefore, some of the face masks were also analyzed using a Bruker Vertex 70 FT-IR (Ettlingen, Germany) with a scanning range of $400-4000 \mathrm{~cm}^{-1}$ in the central laboratory of Niğde Ömer Halisdemir University to confirm the particles as plastic and identify their polymer type (Lenz et al. 2015). It was determined that the masks collected from all 3 cities were generally in 3 different colors. These were white, green, and blue. Three different masks belonging to these three colors were taken from each city and analyzed.

For several decades, the carbonyl index has been used to monitor polypropylene-polyethylene photooxidation and calculate the deterioration of its mechanical properties (Rouillon et al. 2016). Therefore, the relative levels of surface oxidation and relative ages of face masks were determined by calculating the carbonyl indexes of the polyethylene and polypropylene by the following equation:

Carbonyl index $(\mathrm{CI})=\frac{A_{1}}{A_{2}}$

where $A_{1}$ is the absorbance at $1715-1735 \mathrm{~cm}^{-1}$, carbonyl group; and $A_{2}$ is the absorbance at $1471 / 1460 / 1452 / 1495$ $\mathrm{cm}^{-1}$ — reference peaks of each polymer — , respectively (Wang et al. 2009; Rodrigues et al. 2018)

The level of fragmentation in the fibers was important to show the seriousness of the microplastic threat problem. Hence, SEM images were recorded using a Zeiss/EVO 40 (Baden-Württemberg, Germany). All samples were coated with a light coating of conductive gold before analysis to prevent sample charging.

In addition, weighing analyses were carried out in order to determine the total microplastic potential of face masks. The weighing process was carried out with a precision scale (ISOLAB-60231002). The mask to be weighed was placed in the weighing container in the scale, respectively. The weighing results have been recorded. In this way, the weight of the plastic waste will be determined in the real amount.

\section{Results and discussion}

\section{Face mask density and distribution}

The locations of the collected masks are shown on the map given in Fig. 2.

According to these results, the estimated number of masks per $\mathrm{km}^{2}$ in the cities was calculated as 96.2 pieces $/ \mathrm{km}^{2}$ for Adana, 68.4 pieces $/ \mathrm{km}^{2}$ for Mersin, and 29.9 pieces $/ \mathrm{km}^{2}$ for Niğde. However, the actual face mask data obtained in this real case study were as follows: 210 for Adana, 170 for Mersin, and 166 for Niğde. Masks were collected simultaneously from cities. The difference between the results indicated serious plastic pollution, especially in the city centers, and a lack of waste management. It was determined that the three cities used roughly 2.5 million face masks a day. Assuming that each face mask weighs 4 grams, 10 tons of face masks are generated as waste per day. Approximately 300 tons of plastic waste are produced per month, with most entering the soil/aquatic ecosystem and in turn threatening nature. The number of masks used in the three cities was calculated as given in Table 1. According to these results, approximately 50 million contaminated face masks were created each day in Turkey. This value also means 73,000 tons of contaminated waste per year. Akber Abbasi et al. (2020) also reported that there is a significant increase of (micro) plastic content in the Arabian Peninsula.

Saudi Arabia, being the most populated country in the region, may contribute up to 32-235 thousand tons of (micro) plastic.

Table 2 shows the number of masks collected from the streets in the cities. Accordingly, most masks were collected in Adana with 210 masks $/ \mathrm{km}^{2}$, which was followed by 170 masks $/ \mathrm{km}^{2}$ in Mersin and $166 \mathrm{masks} / \mathrm{km}^{2}$ in Niğde. According to the data, the average mask weight was determined in Niğde with $3.0607( \pm 0.4340) \mathrm{g} / \mathrm{mask}$, while it was $2.9914( \pm 0.4315) \mathrm{g} / \mathrm{mask}$ in Adana and $2.9554( \pm 0.5101) \mathrm{g} /$ mask in Mersin (Fig. 3.). As can be seen from Fig. 3, the change in the number of masks shows how the mass weight

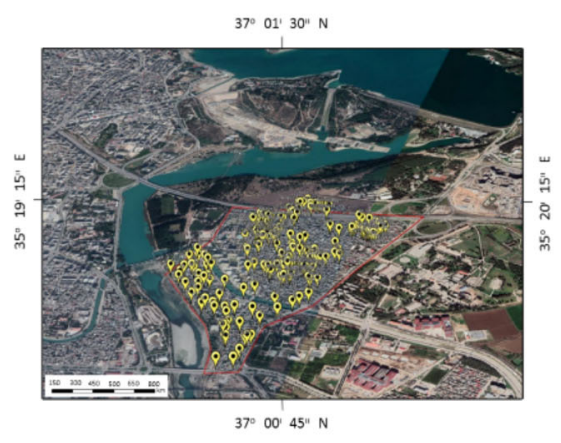

Adana

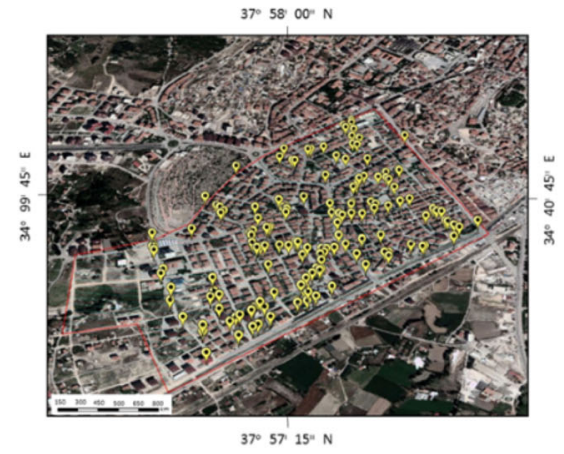

Niğde

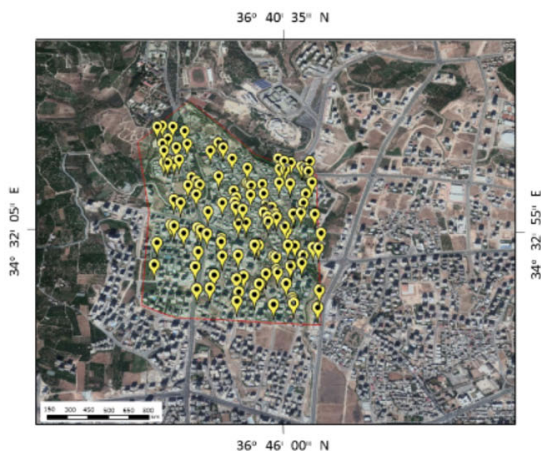

Mersin

Fig. 2 Coordinates and locations of the study area on the map 
Table 1 Estimated daily face mask use in the three cities

\begin{tabular}{|c|c|c|c|c|c|c|c|c|c|}
\hline City & Population & $\begin{array}{l}\text { Urban } \\
\text { population }^{\mathrm{a}}\end{array}$ & $\begin{array}{l}\text { Face } \\
\text { masks' } \\
\text { acceptance } \\
\text { rate }\end{array}$ & $\begin{array}{l}\text { Number of face masks used by } \\
\text { each member of the general } \\
\text { population each day }\end{array}$ & $\begin{array}{l}\text { Total daily } \\
\text { face mask } \\
\text { use (pieces) }\end{array}$ & $\begin{array}{l}\text { Average face } \\
\text { mask weight } \\
\text { (theoretical) }(g)\end{array}$ & $\begin{array}{l}\text { Theoretical } \\
\text { face mask } \\
\text { waste } \\
\text { (tons/day) }\end{array}$ & $\begin{array}{l}\text { Surface } \\
\text { area } \\
\left(\mathrm{km}^{2}\right)\end{array}$ & $\begin{array}{l}\text { Face } \\
\text { masks } \\
\text { per km² }\end{array}$ \\
\hline Adana & $2,237,940$ & $74.4 \%$ & $80 \%$ & 1 & $1,332,022$ & 4 & 5.3 & 13,844 & 96 \\
\hline Mersin & $1,840,425$ & $74.4 \%$ & $80 \%$ & 1 & $1,095,421$ & 4 & 4.4 & 16,010 & 68 \\
\hline Niğde & 362,861 & $74.4 \%$ & $80 \%$ & 1 & 215,975 & 4 & 0.9 & 7234 & 30 \\
\hline Turkey & $83,154,997$ & $74.4 \%$ & $80 \%$ & 1 & $49,493,854$ & 4 & 198 & 783,562 & 63 \\
\hline
\end{tabular}

${ }^{a}$ Data source: retrieved on September 14, 2020, from https://cevreselgostergeler.csb.gov.tr/

can change. As the number of masks increases, the average mass weight of Niğde Province increases while the average mass weight of Mersin Province decreases. Taking into account the number of masks collected, the mask weight per $\mathrm{km}^{2}$ was calculated as $628.194,508.076$, and $502.418 \mathrm{~g} / \mathrm{km}^{2}$ for Adana, Niğde, and Mersin, respectively (Fig.4).

Sangkham (2020) studied the calculation of the formation of face masks and medical waste in some countries in Asia. They drew attention to the problems that these waste masks and medical wastes will cause against the environment. They found that the total medical waste generated in Asia was 16,659.48 tons/day, while it was predicted as 908.07 tons/day in Turkey. The actual amount of mask waste is 200 tons/day in Turkey as seen in the results. According to the data we received from the ministry and the Turkish Statistical Institute, the total amount of medical waste in the previous year and the amount of mask waste calculated in this study are the same. In another study conducted in Wuhan by Singh et al. (2020), the amount of generated medical waste was found as 6 times more than the previous year. Even this ratio shows that the waste management in the country needs updating.

In another study, Ammendolia et al. (2021) collected personal protective equipment from streets in the province of Ontario, Toronto, Canada. They reported that they found 95\% of disposable face masks, $3 \%$ reusable masks, and only 2 high-grade masks such as N95 and KN95. However, N95, $\mathrm{KN} 95$, and reusable masks were not found in any of these 3 cities in this study.
A similar perspective was stated by Ouhsine et al. (2020). According to the study, they reported that $87 \%$ of COVID-19 protective equipment were mixed with domestic organic wastes in Khenifra and Tighassaline cities. It is thought that the reaching of disposable face masks and other protective equipment to the disposal points will affect the occupancy rates in the capacity of the solid waste disposal facilities that are planned based on population. Okuku et al. (2021) emphasized that the protective equipment they encountered on the streets would come to an end in the seas, and new waste management should be developed in this direction. Studies from all over the world show that special waste management should be developed as soon as possible for the environmental risks of plastic waste after the COVID-19 outbreak.

\section{Experimental validation by chemical and physical structure analyses}

Most studies carried out on plastic identification ignore the spectral change caused by plastic degradation when comparing plastic with the reference spectral library. Environmental exposure can cause polymer aging and mechanical and oxidative decomposition of the plastic surface (Xu et al. 2019). Some studies have also reported the changes in the infrared spectrum results due to weather conditions (Rajakumar et al. 2009; Brandon et al. 2016). It can also lead to underestimated results due to the use of polymers with different percentage content of the fibers because of the limited amount of

Table 2 The number and weight of the face masks found per $\mathrm{km}^{2}$ in the three cities

\begin{tabular}{|c|c|c|c|c|c|c|}
\hline \multirow[t]{2}{*}{ City } & \multicolumn{3}{|l|}{ Theoretical } & \multicolumn{3}{|l|}{ Experimental } \\
\hline & $\begin{array}{l}\text { Face mask average } \\
\text { weight }(\mathrm{g})\end{array}$ & $\begin{array}{l}\text { Face masks } \\
\text { per } \mathrm{km}^{2}\end{array}$ & $\begin{array}{l}\text { Weight of face } \\
\text { masks per } \mathrm{km}^{2} \mathrm{~g} / \mathrm{km}^{2} \text { ) }\end{array}$ & $\begin{array}{l}\text { Face mask average } \\
\text { weight }(\mathrm{g})\end{array}$ & $\begin{array}{l}\text { Face masks } \\
\text { per } \mathrm{km}^{2}\end{array}$ & $\begin{array}{l}\text { Weight of face masks } \\
\text { per } \mathrm{km}^{2}\left(\mathrm{~g} / \mathrm{km}^{2}\right)\end{array}$ \\
\hline Mersin & 4 & 96.2 & 384.8 & 2.955 & 170 & 502.418 \\
\hline Adana & 4 & 68.4 & 273.6 & 2.991 & 210 & 628.194 \\
\hline Niğde & 4 & 29.9 & 119.6 & 3.061 & 166 & 508.076 \\
\hline
\end{tabular}


Fig. 3 Weight and percentage distribution of the 50 masks randomly selected for each city

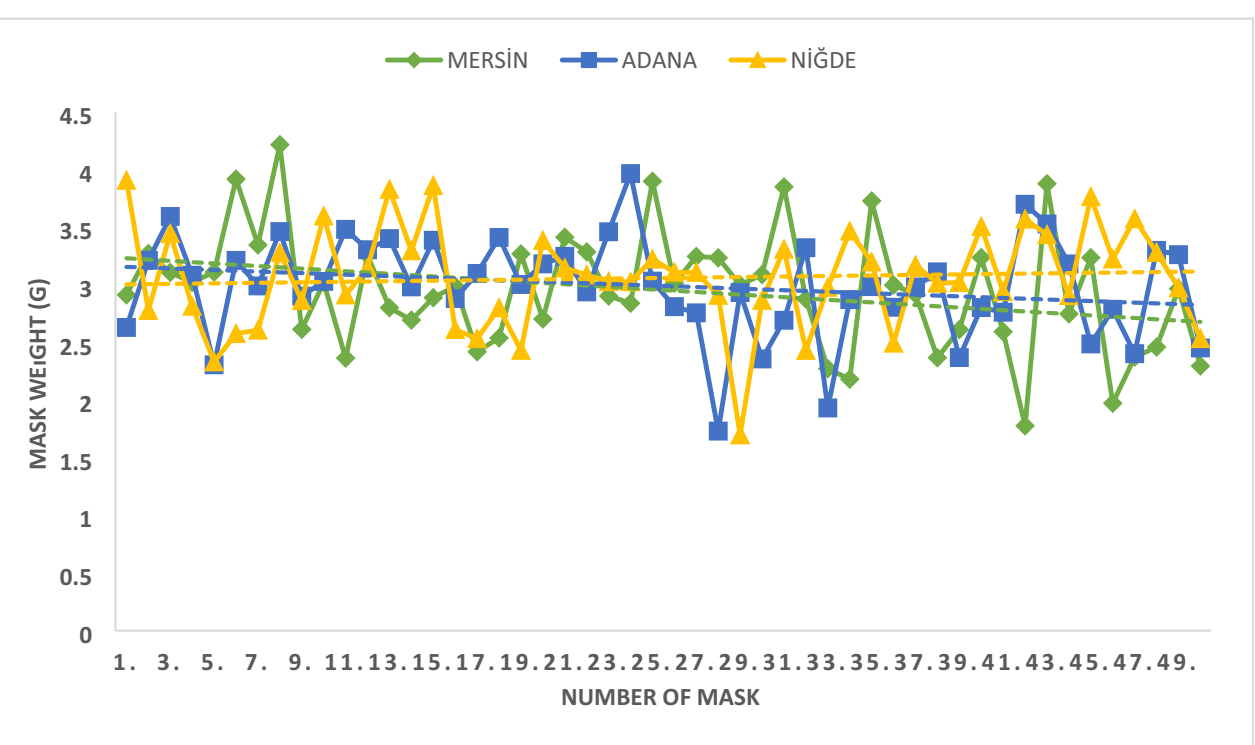

reference polymers used. The changes in the infrared spectrum results were also observed in this study.

The results showed that the surface of $83.3 \%$ of the face masks was polypropylene, while $16.7 \%$ of them was polyethylene (Fig. 5). No structural relationship was found between the three colors. Also, there was no significant relationship between the products weighed and the polymer type. However, while the most common mask color was white, it was determined that all white masks were polypropylene.
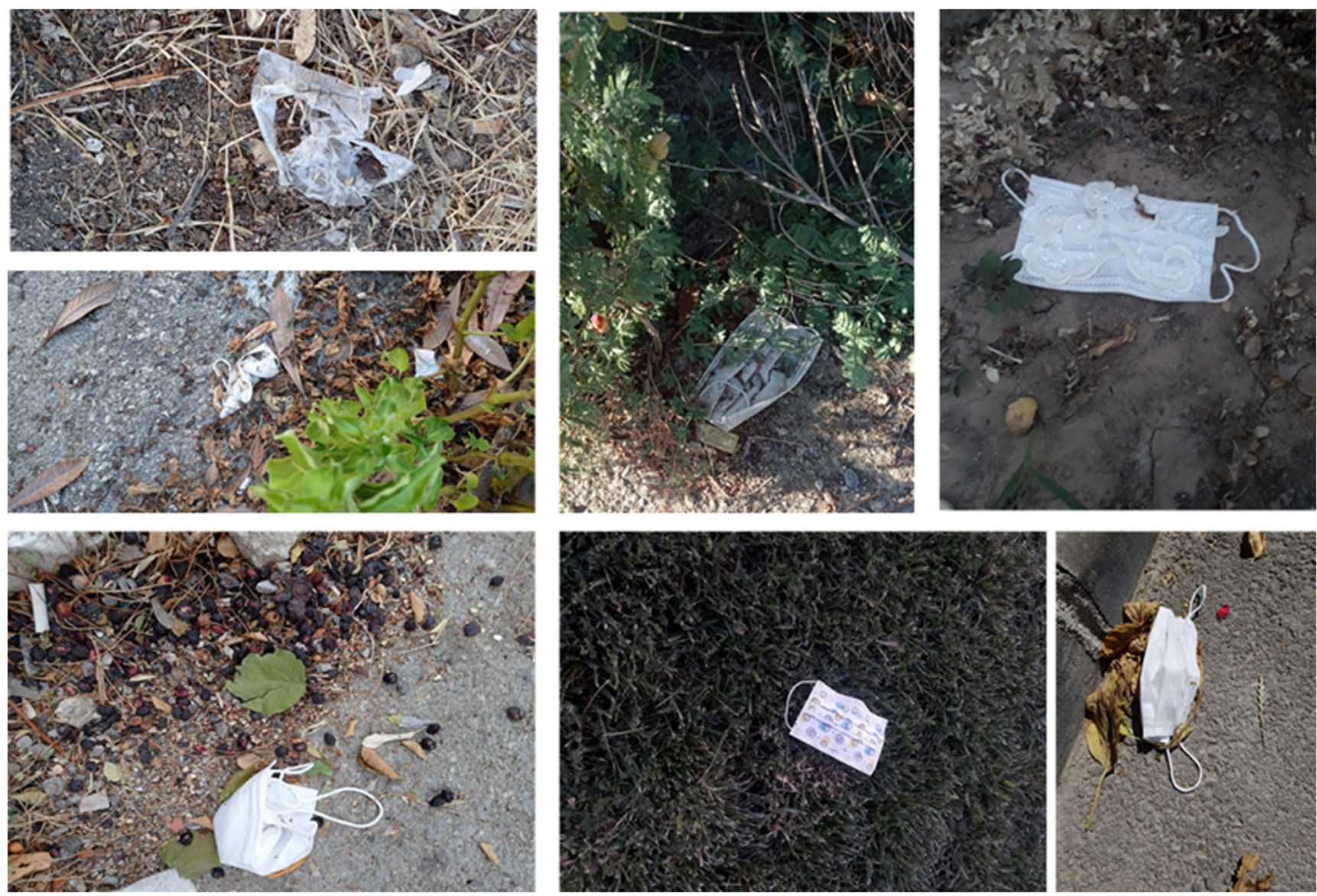

Fig. 4 Examples of the different colors and types of masks collected from the streets of the three cities 

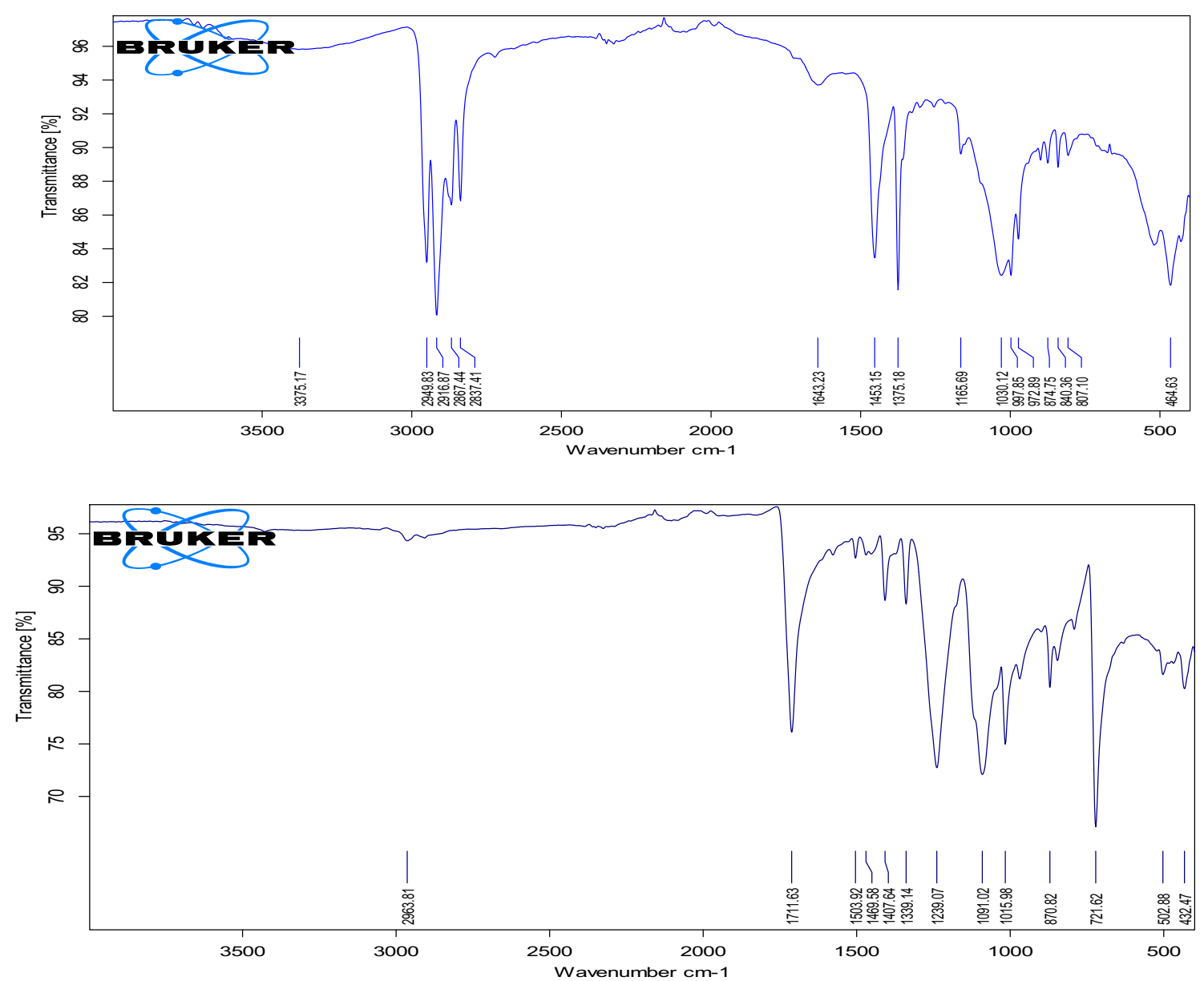

Fig. 5 FT-IR spectra of the dominant polymer types including polypropylene (top) and polyethylene (bottom)

Chae and An (2018) emphasized the urgent need for studies in the field of plastic pollution regarding soil and stated that the PE and PA polymer types had a high potential to transport to the soil environment.

Due to their different surface areas and densities, some of the microplastics that reach the water ecosystem remain on the water surface, while others in fiber form reach the sediment. Tsang et al. (2017) detected $0.4 \%$ fiber in the microplastic analysis of coastal waters in Hong Kong between June 2015 and June 2016 and microplastics with a fiber structure of $6.3 \%$ in the sedimentation. Besides, according to the results of their FT-IR analysis, $50.9 \%$ of the 240 different microplastics were PP polymer type.

Khoironi et al. (2020) investigated the degradation of PP in the sea at depths between 50 and $170 \mathrm{~m}$ and in the bottom sedimentation. They reported that the PP in the bottom sediment was mostly in the formation of microplastics as a result of plastic degradation.

When the results are examined in particular for Adana and Mersin, it is possible to associate them with the previous microplastic studies in the northeast Mediterranean. Similar results were reported in the study of Gündoğdu et al. (2018) on the Levantine coast in the same region. They determined that $87.5 \%$ of the microplastic samples were either polyethylene or polypropylene. Both studies also found that the largest source of microplastics was fiber. According to the studies in the literature, the most common type of plastic is polyethylene (up to $51 \%$ ), followed by polypropylene (up to $27 \%$ ) (Sun et al. 2019). However, when it comes to fiber, there have been studies that were unable to detect polyethylene (Lares et al. 2018). Akarsu et al. (2020) carried out an FT-IR analysis on microplastic samples taken from the sea surface and sediment in Mersin Bay, which is located in the Northeast Mediterranean. They examined fibers among the plastic samples taken from the treatment plant effluent; the most common type of plastic was polypropylene and none of the fibers were polyethylene, in line with the literature.

In general, prioritizing human health over environmental health due to the global state of emergency caused the postponement of policies to reduce the use of plastic (Patrício Silva et al. 2020). Polypropylene and polyethylene are the most common types of polymers and continue to be the most common types of plastic found in nature. As a result, the environmental footprint of plastics is increasing. In order to eliminate this problem, alternative studies, particularly those regarding the reusability of these polymer types, must be accelerated. 
SEM is used to obtain information about the surface structure, characteristics, and elemental composition of any material or particle. SEM is significant in determining the effect of environmental exposure on the surface texture (Wang et al. 2017). Characteristic cracks and deteriorations on the surface of microplastics can be revealed with SEM imaging. Grooves and gouges formed by mechanical aging processes can also be observed (Zbyszewski et al. 2014).

FT-IR-based absorbance results were also used to assess the relative levels of surface oxidation and relative age of polymers in 27 face masks (Table S1). The carbonyl index (CI) values of 27 face masks of PP and PE ranged from 0.213 to 0.329 and 0.105 to 0.195 , respectively (Figure S1). As expected, polyethylene was less oxidized. Literature studies show that polyethylene is more durable than polypropylene. Rodrigues et al. (2018) also studied the calculation of carbonyl index (CI) values of microplastics (MPs) and reported that PE particles were less oxidized than PP. The carbonyl index is often used to measure the photooxidation caused by light with respect to the gradual aging of the polymer. This method has a high success rate, especially in polypropylene and polyethylene. It was determined that only $25 \%$ of the samples was highly oxidized. The important reason for this is maybe the indication that the samples do not spend too much time in the environment. However, considering that the study was conducted in June, the results are fairly consistent due to the high sunlight intensity and temperature.

SEM analysis was performed directly on the samples after FT-IR. Polymer structures can differ in durability, solubility, fragmentation, and rupture. As can be seen from Fig. 6, there were polymer ruptures in their structure. These ruptured polymers can form small micropolymer structures after the disintegration process, and these micropolymer structures can cause plastic pollution in seas and soils.

The face masks collected from bushes or soil surfaces appeared to have similar morphologies. The samples of these masks made of polypropylene (magnified to $100 \times 1000$ ) did not appear to be shatter resistant. Studies in the literature on polypropylene wastes have reported that polypropylene is not as durable as polyethylene and that changes such as breakage or deterioration occur in polypropylene (Ó Briain et al. 2020). This shows that face masks, which are classified as macroplastic, can turn into microplastic dimensions more easily.

Most of the face masks were found around bus stops, hospitals, pharmacies, and playgrounds. As protective equipment such as face masks and gloves are considered to be medical waste, the best disposal method for such equipment is incineration. However, due to insufficient incineration facilities, medical waste is being buried, which is not an environmentally effective method of disposal. Single-use face masks contain large amounts of polypropylene, which release a lot of toxic substances including stabilizers and pigments (Hahladakis et al. 2018). The main problems in the world regarding this subject are the lack of medical waste bins for protective equipment and the lack of awareness. Most people consider masks to be similar to small clothes rather than plastic products and therefore harmless to the environment. However, small clothes also contain MPs (e.g., microfibers of nylon). Medical waste bins have been placed in various closed areas. As an alternative to medical waste bins, it can be proposed as a solution to the management of waste masks by placing especially marked/colored garbage cans on the streets and collecting waste masks used by people and throwing them into boxes.

\section{Conclusion}

In this study, more masks than expected were detected in all three cities. An average of 182 masks $/ \mathrm{km}^{2}$ was found in each city. It was determined that the face mask pollution per unit area was $24.3 \%$ higher in Adana compared to the other two cities. However, it should be noted that a high number of masks, almost the same amount as in Mersin, were detected in Niğde, which has a smaller population compared to the other two cities and therefore lower consumption dynamics.

It is almost impossible to determine the sources of face masks that have been thrown into the environment, and it is also extremely difficult to take preventive measures. Therefore, for the environmentally successful execution of the pandemic that will last for many years, it is necessary to accurately manage the 300 tons of discarded face masks in these three cities and 60,000 tons in Turkey for a month. New legislation and regulations on disposable face mask management should be introduced to minimize the effect of face masks that cause both visual and environmental pollutions.

It was determined that the highest polymer type of face mask examined was polypropylene with $83.3 \%$. It has been observed that there is no color-polymer type relationship. Again, there is no significant relationship between the polymer type and the mask weight. As stated in the literature, the change in polymer peaks was also seen in this study. However, the relationship between mask type and polymer type could not be established.

Carbonyl index analysis was performed on face masks, and the results ranged from 0.105 to 0.329 . As stated in the literature, it has been observed that the oxidation values of polyethylene are lower. Only 1 in 4 of the samples were found to be highly oxidized, and this is because the masks spent less time in the environment.

Another thing to do is to make the masks more ecofriendly. Nowadays, there are a number of nongovernmental organizations that run a project for recycling surgical face masks to keep them out of landfills (Maren 


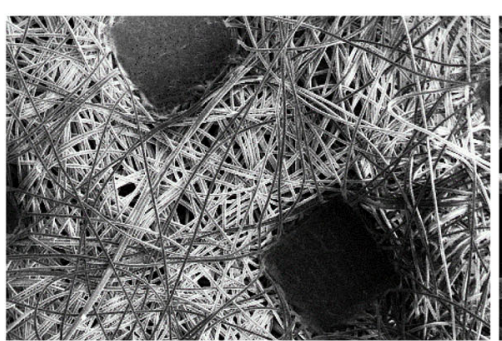

$100 x$

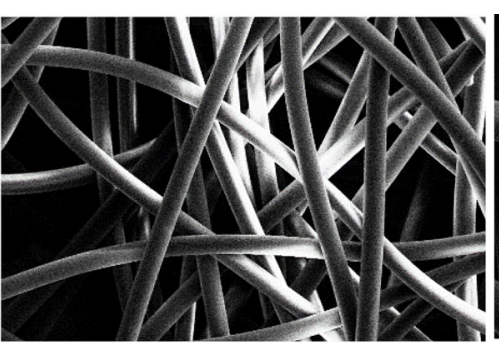

$500 x$

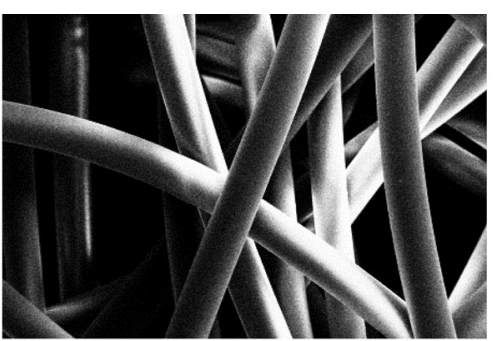

$1000 x$

Unused mask

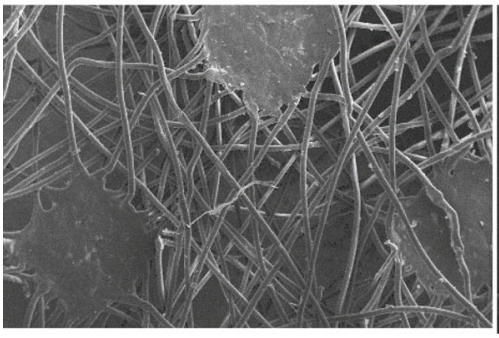

$100 x$

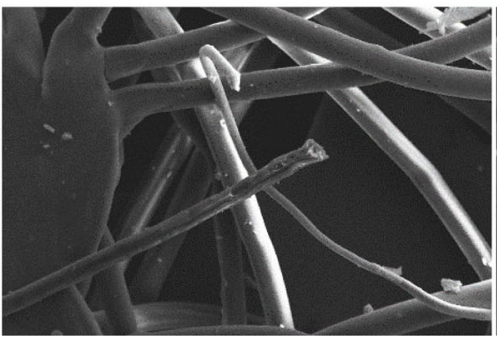

$500 x$

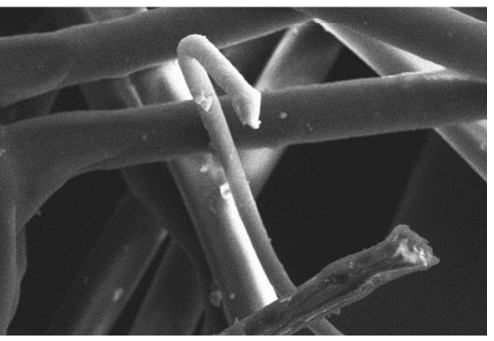

$1000 x$

Mersin

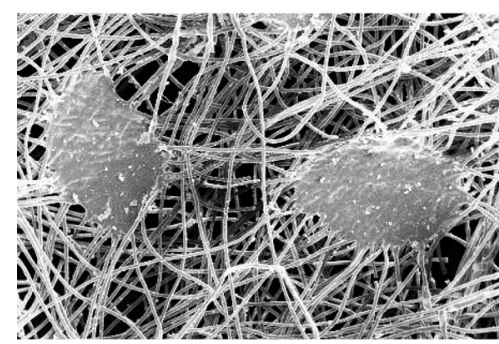

$100 x$

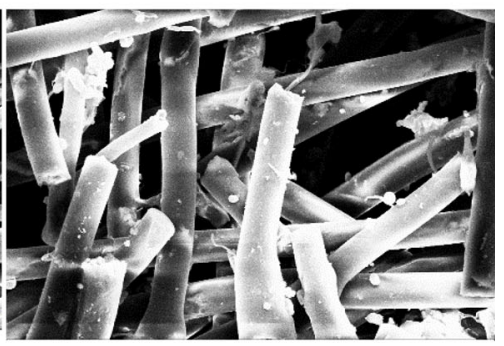

$1000 x$

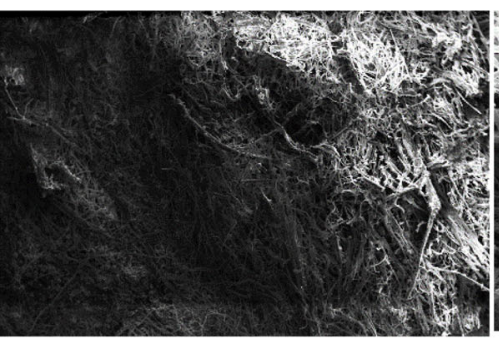

$100 x$
$500 x$

\section{Adana}

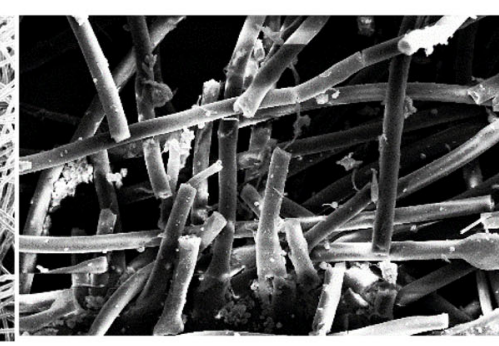

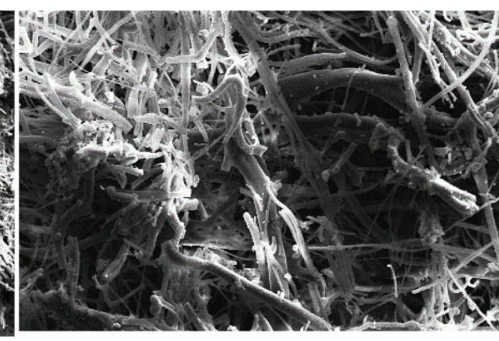

$500 x$

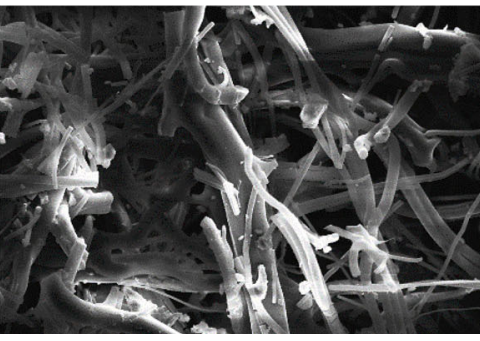

$1000 x$

Niğde

Fig. 6 Scanning electron microscope (SEM) images of the face masks

Berthold 2020; Schulz 2020). Although an academic report on this issue has not yet been presented, the initial results indicate that up to $60 \%$ of face masks can be recycled. However, it is not feasible to develop a separation system yet. Another alternative solution would be to use bio-based polymers. Hemp is primarily used to create a single-use face mask. However, there is not enough raw material to produce enough for the whole world or even a single country. Therefore, the importance of studies on reusable masks is increasing day by day. 
Supplementary Information The online version contains supplementary material available at https://doi.org/10.1007/s11356-021-14099-8.

Author contribution CA, EUD, and ÖM contributed to the study conception and design. Material preparation and analysis were performed by ÖM and CA. EUD wrote the manuscript with support from CA, and all authors commented on previous versions of the manuscript. All authors read and approved the final manuscript.

Data availability Data sharing does not apply to this article as no datasets were generated or analyzed during the current study.

\section{Declarations}

Ethics approval and consent to participate Not applicable.

Consent for publication Not applicable.

Competing interests The authors declare no competing interests

\section{References}

Akarsu C, Kumbur H, Gökdağ K, Kideyș AE, Sanchez-Vidal A (2020) Microplastics composition and load from three wastewater treatment plants discharging into Mersin Bay, north eastern Mediterranean Sea. Mar Pollut Bull 150:110776. https://doi.org/10.1016/j. marpolbul.2019.110776

Akber Abbasi S, Khalil AB, Arslan M (2020) Extensive use of face masks during COVID-19 pandemic: (micro-)plastic pollution and potential health concerns in the Arabian Peninsula. Saudi J Biol Sci 27:3181-3186. https://doi.org/10.1016/j.sjbs.2020.09.054

Ammendolia J, Saturno J, Brooks AL, Jacobs S, Jambeck JR (2021) An emerging source of plastic pollution: environmental presence of plastic personal protective equipment (PPE) debris related to COVID-19 in a metropolitan city. Environ Pollut 269:116160. https://doi.org/10.1016/j.envpol.2020.116160

Aragaw TA (2020) Surgical face masks as a potential source for microplastic pollution in the COVID-19 scenario. Mar Pollut Bull 159:111517. https://doi.org/10.1016/j.marpolbul.2020.111517

Barnes David KA, Francois G, Thompson Richard CBM (2009) Accumulation and fragmentation of plastic debris in global environments. Philos Trans R Soc Biol Sci 364:1985-1998. https://doi.org/ 10.1098/rstb.2008.0205

Maren Berthold (2020) Plaxtil: A French firm finds a way to recycle single-use face masks. In: RESET

Brandon J, Goldstein M, Ohman MD (2016) Long-term aging and degradation of microplastic particles: comparing in situ oceanic and experimental weathering patterns. Mar Pollut Bull 110:299-308. https://doi.org/10.1016/j.marpolbul.2016.06.048

Brando V, Braga F, Scarpa GM (2020). Covid-19 reveals human impact on environment: example of Venice water transparency seen by Copernicus. Copernicus Marine Service, CNR-ISMAR, Rome H2020 Coast Project.

Chae Y, An YJ (2018) Current research trends on plastic pollution and ecological impacts on the soil ecosystem: a review. Environ Pollut 240:387-395. https://doi.org/10.1016/j.envpol.2018.05.008

Chintalapudi N, Battineni G, Amenta F (2020) COVID-19 virus outbreak forecasting of registered and recovered cases after sixty day lockdown in Italy: a data driven model approach. J Microbiol Immunol Infect 53:396-403. https://doi.org/10.1016/j.jmii.2020.04.004
Corcoran PL, Biesinger MC, Grifi M (2009) Plastics and beaches: a degrading relationship. Mar Pollut Bull 58:80-84. https://doi.org/ 10.1016/j.marpolbul.2008.08.022

Corradini F, Casado F, Leiva V, Huerta-Lwanga E, Geissen V (2020) Microplastics occurrence and frequency in soils under different land uses on a regional scale. Sci Total Environ 141917:141917. https:// doi.org/10.1016/j.scitotenv.2020.141917

Dharmaraj S, Ashokkumar V, Hariharan S, et al (2021) The COVID-19 pandemic face mask waste: a blooming threat to the marine environment. Elsevier Enhanced Reader.pdf

Gerolin CR, Pupim FN, Sawakuchi AO, Grohmann CH, Labuto G, Semensatto D (2020) Microplastics in sediments from Amazon rivers, Brazil. Sci Total Environ 749:141604. https://doi.org/10.1016/j. scitotenv.2020.141604

Gregory MR, Andrady AL (2003) Plastics and the environment. John Wiley \& Sons Inc., New Jersey

Gündoğdu S, Çevik C, Ayat B, Aydoğan B, Karaca S (2018) How microplastics quantities increase with flood events? An example from Mersin Bay NE Levantine coast of Turkey. Environ Pollut 239:342-350. https://doi.org/10.1016/j.envpol.2018.04.042

Hahladakis JN, Velis CA, Weber R, Iacovidou E, Purnell P (2018) An overview of chemical additives present in plastics: migration, release, fate and environmental impact during their use, disposal and recycling. J Hazard Mater 344:179-199. https://doi.org/10.1016/j. jhazmat.2017.10.014

Huerta Lwanga E, Gertsen H, Gooren H, Peters P, Salánki T, van der Ploeg M, Besseling E, Koelmans AA, Geissen V (2016) Microplastics in the terrestrial ecosystem: implications for Lumbricus terrestris (Oligochaeta, Lumbricidae). Environ Sci Technol 50:2685-2691. https://doi.org/10.1021/acs.est.5b05478

Jeong CB, Won EJ, Kang HM, Lee MC, Hwang DS, Hwang UK, Zhou B, Souissi S, Lee SJ, Lee JS (2016) Microplastic size-dependent toxicity, oxidative stress induction, and p-JNK and p-p38 activation in the monogonont rotifer (Brachionus koreanus). Environ Sci Technol 50:8849-8857. https://doi.org/10.1021/acs.est.6b01441

Karthik T, Karan C Praba RR (2016) Nonwovens: process, structure, properties and applications

Khoironi A, Hadiyanto H, Anggoro S, Sudarno S (2020) Evaluation of polypropylene plastic degradation and microplastic identification in sediments at Tambak Lorok coastal area, Semarang, Indonesia. Mar Pollut Bull 151:110868. https://doi.org/10.1016/j.marpolbul.2019. 110868

Kumar M, Xiong X, He M, Tsang DCW, Gupta J, Khan E, Harrad S, Hou D, Ok YS, Bolan NS (2020) Microplastics as pollutants in agricultural soils. Environ Pollut 265:114980. https://doi.org/10.1016/j. envpol.2020.114980

Lares M, Ncibi MC, Sillanpää M, Sillanpää M (2018) Occurrence, identification and removal of microplastic particles and fibers in conventional activated sludge process and advanced MBR technology. Water Res 133:236-246. https://doi.org/10.1016/j.watres.2018.01. 049

Lee KW, Shim WJ, Kwon OY, Kang JH (2013) Size-dependent effects of micro polystyrene particles in the marine copepod tigriopus japonicus. Environ Sci Technol 47:11278-11283. https://doi.org/ $10.1021 / \mathrm{es} 401932 \mathrm{~b}$

Lenz R, Enders K, Stedmon CA, Mackenzie DMA, Nielsen TG (2015) A critical assessment of visual identification of marine microplastic using Raman spectroscopy for analysis improvement. Mar Pollut Bull 100:82-91. https://doi.org/10.1016/j.marpolbul.2015.09.026

Lu L, Luo T, Zhao Y, Cai C, Fu Z, Jin Y (2019) Interaction between microplastics and microorganism as well as gut microbiota: a consideration on environmental animal and human health. Sci Total Environ 667:94-100. https://doi.org/10.1016/j.scitotenv.2019.02. 380 
Mask4all (2020) What countries require masks in public or recommend masks? https://masks4all.co/what-countries-require-masks-inpublic/

Moore CJ (2008) Synthetic polymers in the marine environment: a rapidly increasing, long-term threat. Environ Res 108:131-139. https:// doi.org/10.1016/j.envres.2008.07.025

Nzediegwu C, Chang SX (2020) Improper solid waste management increases potential for COVID-19 spread in developing countries. Resour Conserv Recycl 161:104947. https://doi.org/10.1016/j. resconrec.2020.104947

Ó Briain O, Marques Mendes AR, Mc Carron S et al (2020) The role of wet wipes and sanitary towels as a source of white microplastic fibres in the marine environment. Water Res 116021:116021. https://doi.org/10.1016/j.watres.2020.116021

Okuku E, Kiteresi L, Owato G, Otieno K, Mwalugha C, Mbuche M, Gwada B, Nelson A, Chepkemboi P, Achieng Q, Wanjeri V, Ndwiga J, Mulupi L, Omire J (2021) The impacts of COVID-19 pandemic on marine litter pollution along the Kenyan Coast: a synthesis after 100 days following the first reported case in Kenya. Mar Pollut Bull 162: 111840. https://doi.org/10.1016/j.marpolbul.2020.111840

Ouhsine O, Ouigmane A, El L, Aba B, BM IR (2020) Impact of COVID19 on the qualitative and quantitative aspect of household solid waste. Glob J Environ Sci Manag 6:41-52. https://doi.org/10. 22034/GJESM.2019.06.SI.05

Patrício Silva AL, Prata JC, Walker TR, Campos D, Duarte AC, Soares AMVM, Barcelò D, Rocha-Santos T (2020) Rethinking and optimising plastic waste management under COVID-19 pandemic: policy solutions based on redesign and reduction of single-use plastics and personal protective equipment. Sci Total Environ 742: 140565. https://doi.org/10.1016/j.scitotenv.2020.140565

Prata JC, Silva ALP, Walker TR, Duarte AC, Rocha-Santos T (2020) COVID-19 pandemic repercussions on the use and management of plastics. Environ Sci Technol 54:7760-7765. https://doi.org/10. 1021/acs.est.0c02178

Rajakumar K, Sarasvathy V, Thamarai Chelvan A, Chitra R, Vijayakumar CT (2009) Natural weathering studies of polypropylene. J Polym Environ 17:191-202. https://doi.org/10.1007/s10924009-0138-7

Rodrigues MO, Abrantes N, Gonçalves FJM, Nogueira H, Marques JC, Gonçalves AMM (2018) Spatial and temporal distribution of microplastics in water and sediments of a freshwater system (Antuã River, Portugal). Sci Total Environ 633:1549-1559. https://doi.org/10.1016/j.scitotenv.2018.03.233

Rouillon C, Bussiere PO, Desnoux E, Collin S, Vial C, Therias S, Gardette JL (2016) Is carbonyl index a quantitative probe to monitor polypropylene photodegradation? Polym Degrad Stab 128:200 208. https://doi.org/10.1016/j.polymdegradstab.2015.12.011

Sangkham S (2020) Face mask and medical waste disposal during the novel COVID-19 pandemic in Asia. Case Stud Chem Environ Eng 2:100052

Scheurer M, Bigalke M (2018) Microplastics in Swiss floodplain soils. Environ Sci Technol 52:3591-3598. https://doi.org/10.1021/acs.est. $7 \mathrm{~b} 06003$

Schulz B (2020) Enetian launches recycling program for surgical face masks. In: Las Vegas Rev.
Singh N, Tang Y, Zhang Z, Zheng C (2020) COVID-19 waste management: effective and successful measures in Wuhan, China. Resour Conserv Recycl 163:10-11. https://doi.org/10.1016/j.resconrec. 2020.105071

Sun J, Dai X, Wang Q, van Loosdrecht MCM, Ni BJ (2019) Microplastics in wastewater treatment plants: detection, occurrence and removal. Water Res 152:21-37. https://doi.org/10.1016/j. watres.2018.12.050

Tsang YY, Mak CW, Liebich C, Lam SW, Sze ETP, Chan KM (2017) Microplastic pollution in the marine waters and sediments of Hong Kong. Mar Pollut Bull 115:20-28. https://doi.org/10.1016/j. marpolbul.2016.11.003

UNCTAD (2020) Growing plastic pollution in wake of COVID-19: how trade policy can help. In: United Nations Conf. Trade Dev. https:// unctad.org/news/growing-plastic-pollution-wake-covid-19-howtrade-policy-can-help

Velavan TP, Meyer CG (2020) The COVID-19 epidemic. Tropical Med Int Health 25:278-280. https://doi.org/10.1111/tmi.13383

Wang W, Wang Q, Dang W (2009) Durability of a rice-hull — polyethylene composite property change after exposed to UV weathering. J Reinf Plast Compos 28:1813-1822. https://doi.org/10.1177/ 0731684408090574

Wang Z-M, Wagner J, Ghosal S, Bedi G, Wall S (2017) SEM/EDS and optical microscopy analyses of microplastics in ocean trawl and fish guts. Sci Total Environ 603-604:616-626. https://doi.org/10.1016/j. scitotenv.2017.06.047

WHO (2020) Shortage of personal protective equipment endangering health workers worldwide. https://www.who.int/news-room/detail/ 03-03-2020-shortage-of-personal-protective-equipmentendangering-health-workers-worldwide

Xu J-L, Thomas KV, Luo Z, Gowen AA (2019) FTIR and Raman imaging for microplastics analysis: state of the art, challenges and prospects. TrAC Trends Anal Chem 119:115629. https://doi.org/10. 1016/j.trac.2019.115629

Zbyszewski M, Corcoran PL (2011) Distribution and degradation of fresh water plastic particles along the beaches of Lake Huron, Canada. Water Air Soil Pollut 220:365-372. https://doi.org/10.1007/s11270011-0760-6

Zbyszewski M, Corcoran PL, Hockin A (2014) Comparison of the distribution and degradation of plastic debris along shorelines of the Great Lakes, North America. J Great Lakes Res 40:288-299. https:// doi.org/10.1016/j.jglr.2014.02.012

Zhang W, Zeng G, Pan Y, Chen W, Huang W, Chen H, Li Y (2017) Properties of soluble dietary fiber-polysaccharide from papaya peel obtained through alkaline or ultrasound-assisted alkaline extraction. Carbohydr Polym 172:102-112. https://doi.org/10.1016/j.carbpol. 2017.05.030

Zhao M, Liao L, Xiao W, Yu X, Wang H, Wang Q, Lin YL, Kilinc-Balci FS, Price A, Chu L, Chu MC, Chu S, Cui Y (2020) Household materials selection for homemade cloth face coverings and their filtration efficiency enhancement with triboelectric charging. Nano Lett 20:5544-5552. https://doi.org/10.1021/acs.nanolett.0c02211

Publisher's note Springer Nature remains neutral with regard to jurisdictional claims in published maps and institutional affiliations. 